\title{
INTERACTION OF THE LAWS OF ELECTRODYNAMICS IN THE HUBER EFFECT
}

\author{
Anton Silvestrov \\ Department of theoretical Grounds of Electrical Engineering \\ National Technical University of Ukraine «Igor Sikorsky Kyiv Polytechnic Institute» \\ 37 Peremohy ave., Kyiv, Ukraine, 03056 \\ silvestrovanton@gmail.com \\ Dmytro Zimenkov \\ Department of theoretical Grounds of Electrical Engineering \\ National Technical University of Ukraine «Igor Sikorsky Kyiv Polytechnic Institute» \\ 37 Peremohy ave., Kyiv, Ukraine, 03056
}

\begin{abstract}
A complex physical phenomenon, first discovered by engineer J. Huber in 1951, is investigated. From the perspective of an external observer, the phenomenon is as follows: an electric current is passed through the wheel pairs of the car moving from the rail to the rail. The current, passing through the movable contacts of the wheels and rails, creates an additional (up to the moment of inertia) torque. The research task is to explain the reason for the occurrence of torque. Based on the analysis of individual components of the electrodynamic phenomenon discovered by Huber, an algorithm for the successive interaction of the individual components of the effect is found on the basis of the laws of classical electrodynamics: electric, ferromagnetic, and mechanical.

The identity of the effect is explained, both for the wheel pair and for the bearing (Kosyrev-Milroy engine). For the first time, the cause of the appearance of the torque is revealed: relative movement of surface charges in the region of the movable electrical contact to the wheel body and the rails (or balls and guides). Moving charges unevenly magnetized ferromagnetic bodies according to the Biot-Savart-Laplace law. Due to the reduction in the clearance of the oncoming side of the wheel (or balls) and the increase on the trailing side, the pulling force from the oncoming side and, accordingly, the moment are more than on trailing side. The presented theoretical explanations completely correspond to the experimental investigation of the effect carried out by different scientists at different times.
\end{abstract}

Keywords: Huber effect, Kosyrev-Milroy motor, electrodynamics, Biot-Savart-Laplace law, current element, ferromagnetics, motion mechanics.

\section{Introduction}

Despite the large number of experiments of the Kosyrev-Milroy engines from 1951 to the present, there was no theoretical explanation of the effect.

The complexity of the problem consisted in the desire to obtain an accurate mathematical description of the processes in Huber and Kosyrev-Milroy engines. But it is impossible to obtain a physico-mathematical model that is isomorphic to real processes.

As follows from the fundamental laws of the general interaction of elements and the continuity of matter and motion, there are no such things in nature: a linear relationship between individual physical phenomena, autonomous (ideally isolated) objects, stationary deterministic and stochastic processes, physical constants, etc. Therefore sometimes the success of an explanation of this or that phenomenon depends on a reasonable compromise between the accuracy and complexity of its mathematical description. This approach is used by the authors to explain the Huber effect.

Using the laws of classical physics, at a qualitative level, without complex numerical calculations, the logical sequence of the action of the corresponding laws is considered. These laws together provide explanations for the Huber effect in the corresponding engines.

\section{Review of existing attempts to explain the effect}

The explanation of the effect, presented by various scientists, unfortunately, did not correspond to the physical essence of the phenomenon. Thus, it was considered [1, 2], the moment arises from the Ampere-law interaction of the guide currents and the wheels or balls that are located at an 
acute angle. This would create a moment if, on the second wheel of the Huber wheelset or the other side of the bearing ball, the same moment did not have the opposite sign. It was believed [3] that the moment arises from a spark and an increase in air pressure on the trailing side of the contact. To confirm this [3], the bearings were placed in a vacuum hood and the air was gradually evacuated. The movement ceased due to a significant decrease in the heat in the vacuum from the heated balls to $250{ }^{\circ} \mathrm{C}$. This led to their jamming and stopping of Kosyrev-Milroy engine. The author of work [4] for 1982 argued that sparks are not the cause, and in [3] for 1973, the same author believed that the spark was the cause. The negative effect of sparks on the motion is discussed in [5]. If the cause is pneumatic, the wheels or balls could move along non-ferromagnetic guides. However, in the absence of a ferromagnet, the motion ceased. There is an explanation [6] of the appearance of a moment from the thermal deformation of the guides. It allegedly creates a hill with which a ball or wheel rolls. This explanation does not take into account the considerable thermal inertia of the guides. It could only occur for ultra-low velocities $\Omega$. But the moment does not arise with such $\Omega$. In [5] provisions were proposed that do not correspond to the classical laws of physics, for example, the presence of magnetic induction created by a current, and coinciding with it in the direction. Additional ambiguities were made in [7, 8], where the Huber effect is combined with the uncalled effect of J. Searle. The abstract mathematical variational approach in [9] also does not reveal the physics of the phenomenon.

As observations [2] have shown, for the appearance of the torque $\mathrm{M}$, in addition to the presence of motion, it is necessary that the wheels (balls) and the guides are ferromagnetic. In accordance with this, there must be a source of magnetization of the wheels (balls and guides). Magnetization of bodies should be asymmetrical relative to the point of contact: more towards the motion; material of the ferromagnet must be a magnet; lubrication of bearings, if it is not thick, also slightly improves the performance. However, the current I in the "source-consumer" circuit can't directly create an asymmetric magnetic field. The required current is perpendicular to the current I. It would asymmetrically magnetize the ferromagnet. The attraction of the ferromagnets from the oncoming side with subsequent demagnetization would create a torque M. Thus, the explanation of the effect remained unresolved.

\section{Explanation of the effect on the basis of the laws of electrodynamics of moving bodies}

The torque M occurs when there is a motion of the wheel pair of J. Huber [3] or the rotation of the bearings of the Kosyrev-Milroy engine [1] and the current in the contacts of the wheels (or balls) with the guides. The rotation velocity $\Omega$ increases with increasing current I. It does not depend on its direction, constancy or sinusoidal current; is equal to 0 if the material is not ferromagnetic. In addition, if the voltage of the power supply is unchanged, the dependence of $\mathrm{M}$ on $\Omega$ is extremal. For $\Omega=0, M=0$, then $M$ increases to the maximum $\left(M_{\max }\right)$. Further, if the mechanical moment of counteraction is less than $\mathrm{M}_{\max }$, the angular velocity $\Omega$ continues to grow, but $\mathrm{M}$ decreases. Further, if the counter-moment changes sign, at some synchronous velocity $\Omega_{\mathrm{s}}, \mathrm{M}=0$, and then, with increasing $\Omega>\Omega_{\mathrm{s}}, \mathrm{M}<0$.

The specificity of electrodynamics $[10,11]$ consists in the study of a spatially inhomogeneous system with a non-uniform charge distribution $\mathrm{q}$ and additional degrees of motion freedom. That is, the power indicators of the system depend not only on the current I, but on the position and motion of the components of the system.

Let's consider "guides - contact zone - wheel or ball" system. Wheels or balls of radius $r$ rotate with angular velocity $\Omega$ counterclockwise. They roll along fixed guides to the left of the point of contact with the linear velocity $\mathrm{V}_{0}$ :

$$
\mathrm{V}_{0}=\Omega \cdot \mathrm{r} .
$$

In the Huber wheel pair, the rails have a significant previous cross section (relative to the contact area of the rails with the wheel). Therefore, the voltage drop in the rail relative to the drop in the contact area is not significant, and the voltage at the contact is almost independent of the place of rail connection to the source. The cross-sectional areas of the wheel and shaft are also large and 
have an electrical resistance much less resistance of the contact spot. A similar situation occurs in bearings. Therefore, almost all of the source voltage is applied to the contacts of the wheels, or bearings. Therefore, it is necessary to analyze the processes in the contact zone.

\section{1. Flow I of electricity $q$ through the fixed contact zone}

The contact zone is not an ideal line for the wheel or a point for the ball (Fig. 1). It has a finite area " $a$ " of non-ideal (due to the roughness of the surface) of the electromechanical contact that surrounds the " $b$ " area of a purely electrical contact through a small air or oil gap.

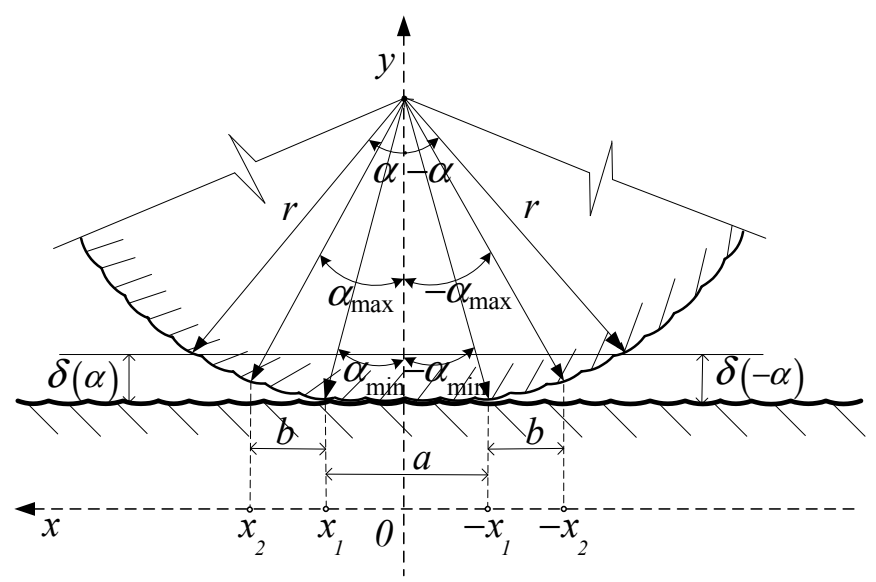

Fig. 1. Contact zone: $a$ - electromechanical, $b$ - electric

Within $\pm \mathrm{x}_{1}$ in zone " $a$ ", as a result of surface roughness, there is a mechanical contact with resistive resistance $\mathrm{R}_{\mathrm{a}}$ and air with a capacitance of $\mathrm{C}_{\mathrm{a}}$. Resistance $\mathrm{R}_{\mathrm{a}}$ depends on the zone of direct contact of the surfaces, the resistivity $\rho_{\mathrm{K}}$ of the contact medium and the average thickness $1_{\mathrm{K}}$ of the mechanical contact zone:

$$
\mathrm{R}_{\mathrm{a}} \cong \frac{\rho_{\mathrm{k}} 1_{\mathrm{k}}}{\mathrm{S}_{\mathrm{k}}}
$$

The capacity $\mathrm{C}_{\mathrm{a}}$ in zone " $a$ " is indicated by the non-ideal contact, that is, the presence of a micro-gap between the surfaces. It is proportional to the part $\mathrm{S}_{\mathrm{a}}$ of the area $\mathrm{S}_{\mathrm{k}}$, the permittivity $\varepsilon$ of air and inversely proportional to the thickness $\delta(\alpha)$ of the micro-gap:

$$
\mathrm{C}_{\mathrm{a}} \cong \frac{\varepsilon \mathrm{S}_{\mathrm{a}}}{\delta(\alpha)}
$$

for contact of balls and cages, taking into account the smallness of $\alpha$,

$$
\mathrm{S}_{\mathrm{a}}=\mathrm{k} \frac{\pi \mathrm{a}^{2}}{4}=\frac{\pi \mathrm{k}}{4} \mathrm{r}^{2} \sin ^{2} \alpha \cong \frac{\pi \mathrm{k}}{4} \mathrm{r}^{2} \alpha^{2},
$$

for contact of wheel and rail

$$
\mathrm{S}_{\mathrm{a}}=2 \mathrm{kaf} \cong 2 \mathrm{kfr} \alpha
$$

where the coefficient $\mathrm{k}$ takes into account both a decrease in the total area $\mathrm{S}_{\mathrm{k}}$ and an increase in the surface of the "plates" of the capacitor due to the roughness of the surfaces; $f$ is the wheel width.

The gap $\delta(\alpha)$ for zone "a" is a few microns. Therefore, the capacity $\mathrm{C}_{\mathrm{a}}$, in spite of the small $\mathrm{C}_{\mathrm{a}}$ area, can be quite appreciable, especially for the oil gap. For small $\alpha$, 


$$
\delta(\alpha)=r(1-\cos \alpha) \cong r \alpha^{2}
$$

Capacity (3), taking into account (4) and (6), for n parallel-connected balls:

$$
\mathrm{C}_{\mathrm{a}}=\mathrm{n} \frac{\varepsilon}{\mathrm{r} \alpha^{2}} \cdot \frac{\mathrm{k} \pi}{4} \mathrm{r}^{2} \alpha^{2}=\frac{\mathrm{nk} \pi \varepsilon \mathrm{r}}{4}
$$

Capacity (3) of two wheel and rail contacts, taking into account (5) and (6):

$$
\mathrm{C}_{\mathrm{a}}=2 \frac{\varepsilon}{\mathrm{r}^{2}} \cdot 2 \mathrm{kfr} \alpha=\frac{4 \mathrm{k \varepsilon f}}{\alpha}
$$

Voltage $U_{k}$ (potential difference $\varphi_{1}$ and $\varphi_{2}$ ) on the contact is determined by the resistance (2) and the current I:

$$
\mathrm{U}_{\mathrm{k}}=\varphi_{1}-\varphi_{2}=\mathrm{I} \cdot \mathrm{R}_{\mathrm{k}}
$$

where, due to the presence of two or four (in the bearing pair) contacts connected in series between $( \pm)$ poles of the constant voltage source $U$, the potentials $\varphi_{1}$ and $\varphi_{2}$ will be the same for four or $\varphi_{2}$ will be zero for two consecutive contacts. The area $S_{b}$ in zone " $b$ " (Fig. 1) for a ball:

$$
\mathrm{S}_{\mathrm{b}}=\frac{\mathrm{k} \pi}{2}(\mathrm{a}+2 \mathrm{~b}) \mathrm{b}
$$

for a wheel:

$$
\mathrm{S}_{\mathrm{b}}=2 \mathrm{kfb}
$$

The area $S_{b}$ is much more than $S_{a}$, but the gap (6) is more, because (Fig. 1)

$$
\alpha \in\left[\alpha_{\min }, \alpha_{\max }\right], \alpha_{\text {min }}=\operatorname{arctg} \frac{\mathrm{a}}{2 \mathrm{r}}, \alpha_{\text {max }}=\operatorname{arctg} \frac{\mathrm{b}+\frac{\mathrm{a}}{2}}{\mathrm{r}} .
$$

The approximate value of the capacitance $C_{b}$ for the mean value $\alpha_{a v}$, which is equal to the half sum $\alpha_{\min }$ and $\alpha_{\text {max }}$ :

- for $\mathrm{n}$ ball bearings

$$
\mathrm{C}_{\mathrm{b}} \cong \mathrm{n} \frac{\varepsilon_{0} \varepsilon_{\mathrm{r}}}{\mathrm{r} \cdot \alpha_{\mathrm{av}}^{2}} \cdot \frac{\mathrm{k} \pi}{2}(\mathrm{a}+2 \mathrm{~b}) \mathrm{b} \cong \frac{\mathrm{nk} \pi \varepsilon_{0} \varepsilon_{\mathrm{r}} \mathrm{r}}{1} \cdot \frac{\alpha_{\text {max }}\left(\alpha_{\text {max }}-\alpha_{\text {min }}\right)}{\alpha_{\text {cep }}^{2}} \approx \mathrm{nk} \pi \varepsilon_{0} \varepsilon_{\mathrm{r}} \mathrm{r} \cdot\left(\frac{\alpha_{\max }}{\alpha_{\mathrm{av}}}\right)^{2} ;
$$

- for two contacts of wheels and rails

$$
\mathrm{C}_{\mathrm{b}}=4 \frac{\varepsilon_{0} \varepsilon_{\mathrm{r}}}{\mathrm{r} \alpha_{\mathrm{av}}^{2}} \cdot \mathrm{kfb}
$$

For bearings, the total capacity will be approximately the fate, for the wheels - units of picofarads.

The charges $\mathrm{q}_{1}$ and $\mathrm{q}_{2}$ of the same sign located on the contacting surfaces,

$$
\mathrm{q}_{1}=\mathrm{C} \cdot \varphi_{1}, \quad \mathrm{q}_{1}=\mathrm{C} \cdot \varphi_{2}
$$

in accordance with (3)-(9), will be thousandths of a Coulomb. 


\section{2. Flow I of electricity $q$ through the movable contact zone}

In the absence of motion, the electric current I, like the flow of electricity q, are distributed in zones " $a$ " and " $b$ " (Fig. 1) symmetrically. A small zone " $b$ " is limited by the coordinates $\pm \mathrm{x}_{2}$, under which the phenomenon of gap breakdown disappears. The situation changes significantly (Fig. 2), if the wheel or ball rotates at with velocity $\Omega$, moving with velocity $V_{0}$.

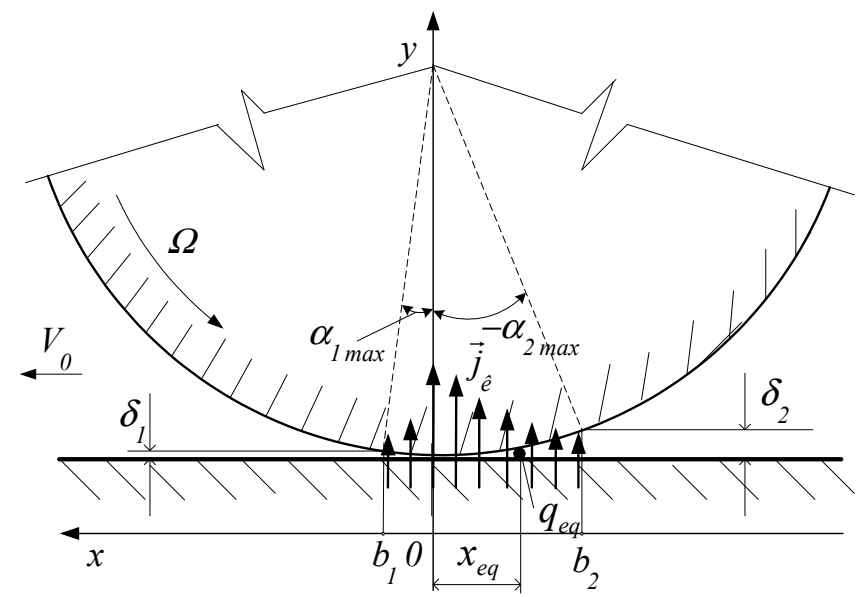

Fig. 2. The asymmetric distribution of the current density I

In order to explain the appearance of asymmetry, let's imagine the flow I by the sum of the electric tubes with density $\vec{j}_{k}$ through the cross sections $\Delta S$ of the total contact zone $S_{k}$ :

$$
I=\int_{S_{k}} \vec{j}(S) \cdot \overrightarrow{d S} \cong \sum_{k=1}^{N} j_{k} \cdot d S
$$

Each k-th current tube $I_{k}$, which is equal to the product of the density $j_{k}$ by the area $\Delta S$, is formed at the moment $\mathrm{t}_{1}$ of the discharge in the gap $\delta_{1}$ and disappears at the moment $\mathrm{t}_{3}$ of the discharge extinction in the gap $\delta_{2}$ (Fig. 3). Having finite length $\delta_{2}$, area $\Delta \mathrm{S}$ of cross-section and location in a ferromagnetic medium, each tube is an $\mathrm{R}_{k} \mathrm{~L}_{\mathrm{k}}$-circle, where $\mathrm{R}_{k}$ and $\mathrm{L}_{k}$ are electrical resistance and inductance. If (for simplicity) let's assume that $\mathrm{R}_{\mathrm{k}}$ and $\mathrm{L}_{\mathrm{k}}$ are constants, and the contact resistance is assumed to be zero for the presence and infinite in the absence of a discharge, then the instantaneous value $i_{k}(t)$ of the current $I_{k}$ is defined as solution of the equation:

$$
\mathrm{L}_{\mathrm{k}} \frac{\mathrm{di}_{\mathrm{k}}}{\mathrm{dt}}+\mathrm{R}_{\mathrm{k}} \cdot \mathrm{i}_{\mathrm{k}}=\mathrm{U}_{\mathrm{k}}
$$

Namely: for time $t$ in the interval between $t_{1}$ and $t_{2}$

$$
i_{k}(t)=\frac{U_{k}}{R_{k}}\left(1-e^{-\frac{t-t_{1}}{\tau_{k}}}\right) \cdot 1\left(t-t_{1}\right)
$$

for

$$
\mathrm{t}_{2} \leq \mathrm{t}<\mathrm{t}_{3}
$$

for time $t$ in the interval between $t_{2}$ and $t_{3}$

$$
i_{k}(t)=\frac{U_{k}}{R_{k}}\left(1-e^{-\frac{t_{2}-t_{1}}{\tau_{k}}}\right) \cdot e^{-\frac{t-t_{2}}{\tau_{k}}} \cdot 1\left(t-t_{2}\right)
$$


where $1\left(\mathrm{t}-\mathrm{t}_{1}\right), 1\left(\mathrm{t}-\mathrm{t}_{2}\right)$ - Heaviside's function, $\tau_{\mathrm{k}}=\mathrm{L}_{\mathrm{k}} / \mathrm{R}_{\mathrm{k}}-$ the time constant.

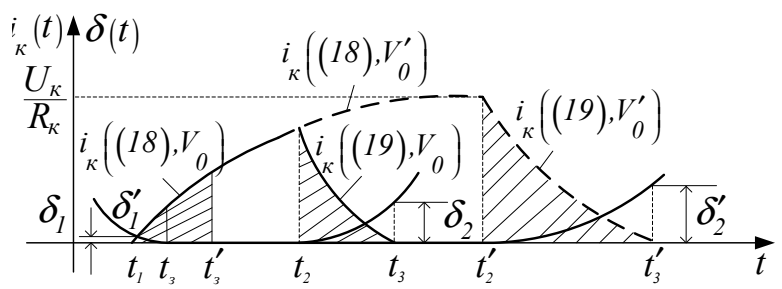

Fig. 3. Transients (18), (19) in the circle of the k-th tube for the velocities $V_{0}$ and $V_{0}^{\prime}$, where $V_{0}>V_{0}^{\prime}$

Depending on the velocity, the current $i_{k}(t)$ in time $\left(t_{2}-t_{1}\right)$ exponentially grows and reaches a steady value $\frac{U_{k}}{R_{k}}$ for velocity $V_{0}^{\prime}$ or part of it $i_{k}\left(t_{2}\right)$ for $V_{0}$.

Further, after the opening of the mechanical contact, when the time $t$ is greater than $t_{2}$ or $t_{2}^{\prime}$, it exponentially decreases (19) to zero.

An intensity $\varepsilon_{\mathrm{br}}$ at which the breakdown of the gap $\delta$ arises or disappears from the oncoming side is equal to the ratio of $\mathrm{U}_{\mathrm{k}}$ to $\delta_{1}$ (Fig. 2). At the moment $\mathrm{t}_{1}$ (regardless of velocity $\mathrm{V}_{0}$ or $\mathrm{V}_{0}^{\prime}$ ), a current (18) appears. The shaded area under the curve $i_{k}(t)$ is equal to the charge $q^{\prime}$ that has passed through the gap in time $\left[t_{1}, t_{3}\right]$ for $V_{0}$ or $\left[t_{1}, t_{3}^{\prime}\right]$ for, where $t_{3}$ is the moment of occurrence of the mechanical contact. Further, at the intervals $\left[t_{3}, t_{2}\right]$ or $\left[t_{3}^{\prime}, t_{2}^{\prime}\right]^{3}$ there is an electromechanical contact. At the moment of time $t_{2}$ or $t_{2}^{\prime}$ a mechanical contact opens and a current (19) arises. It will exponentially decrease until the moment $t_{3}$ or $t_{3}^{\prime}$ at which the ratio $U_{k}+L_{k}\left|\frac{d_{k}}{d t}\right|$ to the gap $\delta$ or $\delta_{2}^{\prime}$ not will be compared to $\varepsilon_{\mathrm{br}}$. It will exponentially decrease until the moment $\mathrm{t}_{3}$ or $\mathrm{t}_{3}^{\prime}$ at which the ratio of the voltage to the gap $\delta$ or $\delta_{2}^{\prime}$ is not compared with $\varepsilon_{\mathrm{br}}$. That is, the gap $\delta_{2}$ will be more than (Fig. 2, 3). The shaded area under the current curve (19) $i_{k}(t)$ is the charge $q^{\prime \prime}$ that has elapsed during the time $\left[\mathrm{t}_{2}, \mathrm{t}_{3}\right]$ or $\left[\mathrm{t}_{2}^{\prime}, \mathrm{t}_{3}^{\prime}\right]$. It is much more than the charge $\mathrm{q}^{\prime}$ from the oncoming side (Fig. 3).

Let's define the distances $b_{1}$ and $b_{2}$. For $b_{1}$ the tension $\varepsilon_{b r}$ at which the gap breaks $\delta_{1}$ :

$$
\varepsilon_{\mathrm{br}}=\frac{\mathrm{U}_{\mathrm{k}}}{\delta_{1}}=\frac{\mathrm{U}_{\mathrm{k}}}{\mathrm{r}\left(1-\cos \alpha_{1}\right)} \cong \frac{\mathrm{U}_{\mathrm{k}}}{\mathrm{r} \alpha_{1}^{2}}=\frac{\mathrm{U}_{\mathrm{k}}}{\mathrm{r}\left(\arcsin \frac{\mathrm{b}_{1}}{\mathrm{r}}\right)^{2}} \cong \frac{\mathrm{U}_{\mathrm{k}}}{\mathrm{b}_{1}^{2}} \cdot \mathrm{r},
$$

therefore

$$
\mathrm{b}_{1}=\sqrt{\frac{\mathrm{U}_{\mathrm{k}} \cdot \mathrm{r}}{\varepsilon_{\mathrm{br}}}}
$$

for $\mathrm{b}_{2}$ :

$$
\varepsilon_{b r}=\frac{U_{k}+L_{k}\left|\frac{d i_{k}\left(t_{3}\right)}{d t}\right|}{\delta_{2}}=\frac{U_{k}+L_{k}\left|\frac{d i_{k}\left(t_{3}\right)}{d t}\right|}{b_{2}^{2}} \cdot r,
$$

therefore

$$
\mathrm{b}_{2}=\sqrt{\frac{\mathrm{U}_{\mathrm{k}}+\mathrm{L}_{\mathrm{k}}\left|\frac{\mathrm{di}_{\mathrm{k}}\left(\mathrm{t}_{3}\right)}{\mathrm{dt} \mid}\right|}{\varepsilon_{\mathrm{br}}}} \cdot \mathrm{r} .
$$


The more $\mathrm{V}_{0}$, the more the module $\frac{\mathrm{di}_{\mathrm{k}}}{\mathrm{dt}}$ and, accordingly, the more ratio of $\mathrm{b}_{2}$ to $\mathrm{b}_{1}$, that is, the non-metering.

In the same way as in a circle with inductance, the current $i_{k}$ of the tubes does not change instantaneously, so the voltage $\mathrm{U}_{\mathrm{k}}$ on the capacitor (3) and, accordingly, the charges $\mathrm{q}_{1}, \mathrm{q}_{2}$ (15) also can't instantaneously change. Therefore, the charges $\mathrm{q}_{1}, \mathrm{q}_{2}$ move to the right of the contact zone.

The current $i_{k}$ of the tubes is overcome with an end hour $\Delta t_{k}$ air gap $\delta_{k}$ with the velocity $\Delta \mathrm{t}_{\mathrm{k}}$ that is proportional to intensity $\varepsilon_{\mathrm{k}}$ :

$$
\overrightarrow{\mathrm{V}}_{\mathrm{k}}=\beta \vec{\varepsilon}_{\mathrm{k}}
$$

where $\beta$ - the mobility coefficient of charged particles in the gap $\delta_{k}$. Then, according to the dimensionality $(\mathrm{A} \cdot \mathrm{s}=\mathrm{C})$, there is an assumption that not only on the surfaces, but also in the gap $\delta_{\mathrm{k}}$ of the $\mathrm{k}$-th tube, an unbalanced charge $\mathrm{q}_{\mathrm{k}}$ is formed (due to the dynamism of the process)

$$
\mathrm{q}_{\mathrm{k}}=\mathrm{i}_{\mathrm{k}} \cdot \Delta \mathrm{t}_{\mathrm{k}}=\mathrm{i}_{\mathrm{k}} \cdot \frac{\delta_{\mathrm{k}}}{\beta \varepsilon_{\mathrm{k}}} \cong \mathrm{i}_{\mathrm{k}} \frac{\delta_{\mathrm{k}}^{2}}{\mathrm{U}_{\mathrm{k}}} .
$$

The total air charge

$$
\mathrm{q}_{\Sigma}=\sum_{\mathrm{k}=1}^{\mathrm{N}} \mathrm{q}_{\mathrm{k}}
$$

can be represented by an equivalent point charge $q_{e}$ equal to $q_{\Sigma}$ and located to the right of the contact point at a distance $\mathrm{x}_{\mathrm{eq}}$ (Fig. 2), where

$$
\mathrm{x}_{\mathrm{eq}}=\frac{\sum_{\mathrm{k}=1}^{\mathrm{N}} \mathrm{q}_{\mathrm{k}} \cdot \mathrm{x}_{\mathrm{k}}}{\mathrm{q}_{\Sigma}} .
$$

Due to asymmetry, surface charges (15) will also be shifted to the right of the contact point.

\section{3. Asymmetric magnetization of the wheel (balls) and the guide by the moving charges}

The charges (15), (25), which are formed in the contact zone, move relative to the wheel bodies (balls) and the guide with velocity $V_{0}$. The product of the total charge $q=q_{1}+q_{2}+q_{\text {eq }}$ per velocity $\mathrm{V}_{0}$ can be represented as an element $\mathrm{I}_{\mathrm{y}} \cdot \Delta \mathrm{x}$ of the conditional current $\mathrm{I}_{\mathrm{c}}$ :

$$
\left(\mathrm{q}_{1}+\mathrm{q}_{2}+\mathrm{q}_{\mathrm{eq}}\right) \cdot \mathrm{V}_{0} \cong \mathrm{I}_{\mathrm{y}} \cdot \Delta \mathrm{x}
$$

where

$$
\mathrm{I}_{\mathrm{c}}=\frac{\mathrm{q}_{1}+\mathrm{q}_{2}+\mathrm{q}_{\mathrm{eq}}}{\Delta \mathrm{t}}, \quad \mathrm{V}_{0}=\frac{\Delta \mathrm{x}}{\Delta \mathrm{t}}
$$

According to the Biot-Savart-Laplace law, the current element $I_{c}(27)$ at the airspace point $\mathrm{M}$ forms the magnetic field of induction $\Delta \mathrm{B}$ (Fig. 4):

$$
\Delta \mathrm{B}=\frac{\mu_{0}}{4 \pi} \cdot \frac{\mathrm{I}_{\mathrm{c}} \cdot \Delta \mathrm{x} \cdot \sin \beta}{\mathrm{r}^{2}}
$$

To calculate the entire magnetic field $\Phi\left(\mathrm{r}, \mathrm{r}_{0}\right)$, it is sufficient to integrate (28) within the limits $\left\{0, \pm \mathrm{r}_{\max }\right\},\left\{0, \mathrm{r}_{0 \max }\right\}$. If the ferromagnetic bodies of the wheel (balls) and the guide are brought into this space, they are locally magnetized, increasing the magnetic induction B by $\mu_{\mathrm{r}}$ (by $1000 \div 10000$ ) and, having an air gap $\delta(\alpha)$, in order to minimize the energy $\mathrm{W}_{\mathrm{M}}$ of the magnetic 
field [9], form the forces $F_{M}$ acting in the case of increase of magnetic conductivity $Y_{M}$, i. e., to reduce the gap $\delta(\alpha)$ :

$$
\mathrm{F}_{\mathrm{M}}=\frac{\mathrm{dW}}{\mathrm{d} \delta}
$$

As is known [10], the force $\mathrm{F}_{\mathrm{M}}$ is proportional to the square of the current $\mathrm{I}_{\mathrm{c}}$, inversely proportional to the square of the gap $\delta(\alpha)$ and acts on the decrease of $\delta(\alpha)$ (increase of $\mathrm{Y}_{\mathrm{M}}$ ).

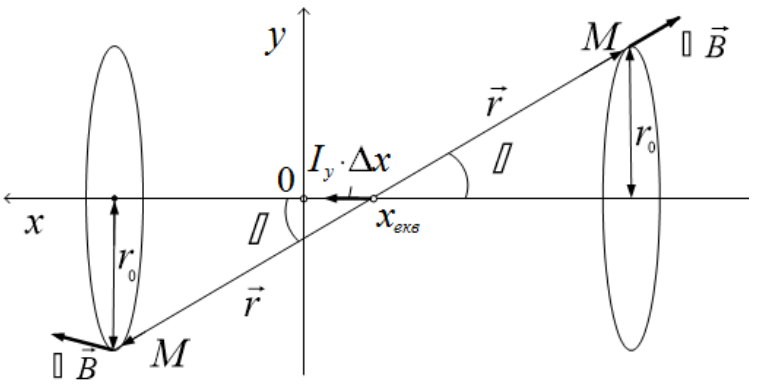

Fig. 4. Creation of a magnetic induction $\Delta \vec{B}$ by an element of a current $I_{y} \cdot \Delta x$

For the moment of time "zero" the shift of the coordinate $\mathrm{x}_{\mathrm{eq}}$ to the right with the same gaps on the left and on the right creates better conditions for magnetization and on the trailing side from the point of contact. If the moving system has zero mass, then the movement to the left would instantaneously cease. Asymmetry (Fig. 2) would be aligned to symmetry (Fig. 1).

However, there is an interaction of four moments for the moment $t_{0}$ of the time t. The moment $\mathrm{M}_{1}$, "wants" to reduce the gap to the left of the contact point; moment $\mathrm{M}_{1}$ "want" to reduce the gap behind the contact point. The dynamic moment $\mathrm{M}_{3}$, which is formed from the mass $\mathrm{m}$ and the velocity $V_{0}$ of motion of the movable part of the system. $M_{4}$ is the moment of loading. If the velocity $\mathrm{V}_{0}$ is more than zero, then

$$
M_{1}+M_{3} \geq M_{2}+M_{4}
$$

The more $\mathrm{m}$ and $\mathrm{V}_{0}$, the more $\mathrm{M}_{3}$, but the more $\mathrm{V}_{0}$, the more the distance $\mathrm{x}_{\text {eq }}$ from the contact point to the coordinate of the equivalent charge $\mathrm{q}_{\text {eq. }}$ (Fig. 4) and, respectively, $\mathrm{M}_{2}$. For a specific current I there exists a maximum velocity $\mathrm{V}_{\max }$ at which the action of the moments averaged over time $\Delta \mathrm{t}$ and the counteraction of the moments $\mathrm{M}_{1}+\mathrm{M}_{3}$ are equalized. For the time interval $\Delta \mathrm{t}$ of time $\mathrm{t}$ at which the inequality (30) is satisfied due to the presence of motion with velocity $\mathrm{V}_{0}$. On the way $\Delta \mathrm{x}$, the moment $\mathrm{M}_{1}$ value averaged over time $\Delta \mathrm{t}$ (due to the reduction of the gap) will increase, and $\mathrm{M}_{2}$ - vice versa (due to the increase of the gap) - will decrease. Such statement is true if the average (over time $\Delta \mathrm{t}$ ) values of the gap on the left $\bar{\delta}_{1}$ are less than on the right $\bar{\delta}_{\mathrm{r}}$ (Fig. 5).

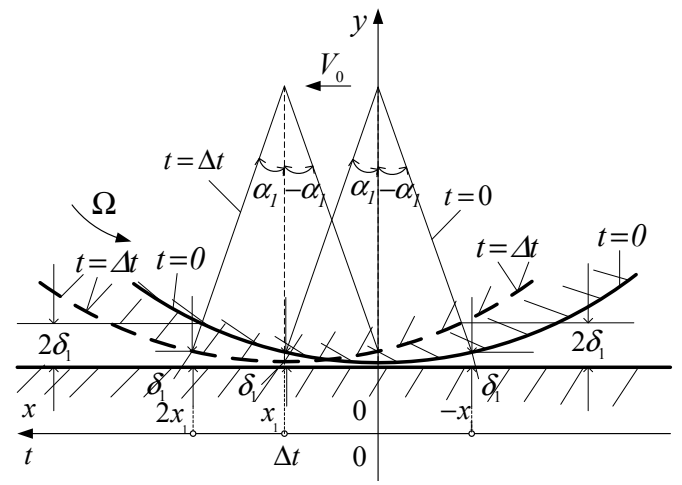

Fig. 5. Dynamics of changes in gaps $\delta(\alpha(t))$ 
Fig. 5 shows the position of the wheel (balls) for the moments $t=0$ (lines) and $t=\Delta t$ (dashed lines) of time $t$. In order to approximately determine the average value over time $\Delta t$ of the gaps to the left and to the right of the point $(\mathrm{t}=0, \mathrm{x}=0)$, the dependences $\delta(\mathrm{t}, \mathrm{x})$ for a small zones $\left[\left(-\mathrm{x}_{1}, \mathrm{x}_{1}\right),(\mathrm{t}=0, \mathrm{t}=\Delta \mathrm{t})\right]$ are linearized (Fig. 6)

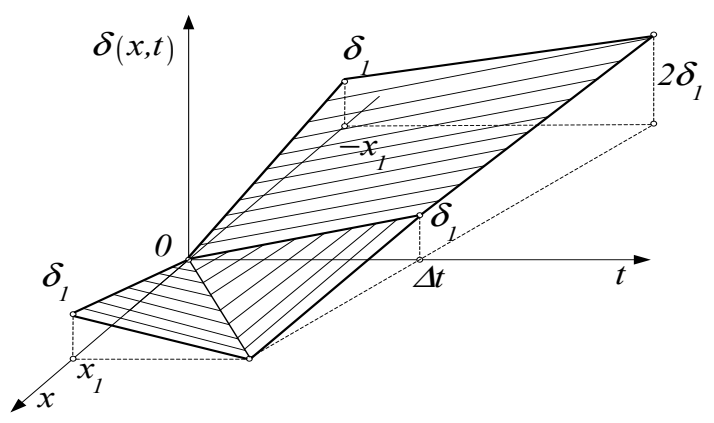

Fig. 6. Surfaces of the linearized dependence $\delta(t, x)$ for the left $\left(x_{1}, \Delta t\right)$ and right $\left(-x_{1}, \Delta t\right)$ zones

A it is followed from Fig. 6 , the average value $\bar{\delta}$ for the time $\Delta \mathrm{t}$ to the left of the point $(0,0)$ is $0,5 \delta_{1}$, on the right $-\delta_{1}$. Accordingly, the average value of the action of the moment $M_{1}$ to the left of the point $(0,0)$ will be 4 times greater than the right for the time $\Delta t$, since the force (29) is inversely proportional to the square of the gap. The asymmetry of forces and moments leads to an acceleration of motion. However, for almost constant parameters $\mathrm{R}_{\mathrm{k}}, \mathrm{L}_{\mathrm{k}}$, that is constant time constant $\tau_{\mathrm{k}}$, asymmetry grows. Center $\mathrm{x}_{\mathrm{eq}}(26)$ of the charge $\mathrm{q}_{\mathrm{eq}}(25)$ is shifted to the right of the contact point $(0,0)$. This leads to a decrease in the asymmetry of the action of the forces and, accordingly, of the total moment, that is, the system has the property of self-balancing. Magnetization can occur both from a constant and sinusoidal current, since the strength of $F_{M}(29)$ depends on its square. A necessary condition for asymmetry is motion. It ensures the condition (30). On the trailing side of contact with zone " $b$ " (Fig. 1), demagnetization of ferromagnets and the gradual disappearance of excess surface charges occur. The effect is increased if the air gap $\varepsilon_{0}$ is replaced by an oil gap with $\varepsilon$ much more than $\varepsilon_{0}$. If further artificially increase the velocity $\Omega$, then the moment will decrease to zero and then change the sign, as in a single-phase asynchronous motor.

\section{Conclusions}

On the basis of the analysis of the existing theoretical explanations and the results of the experiments carried out by the authors of $[1-7,9,12,13]$ and own theoretical and experimental studies, it is first established that:

- the direct cause of asymmetric magnetization of the sections to the left and to the right of the contact point of ferromagnetic bodies is the movement of surface and, possibly, air charges that are formed in the zone of movable electrical contact with the current;

- asymmetrical magnetization together with the mechanical action of the inertia moment of the moving body create the necessary conditions for supporting the movement;

- it is necessary to conduct additional experimental studies to identify the quantitative characteristics of the charge in the contact zone from the current passing through the contact and from specific geometric parameters of the facility for the numerical calculation of the component of the total torque from the magnetization of ferromagnets.

\section{Acknowledgments}

The authors are sincerely grateful to Prof. A. Netushyl [1]. He showed Kosyrev-Milroy engine at the Department of General Electrical Engineering (Kyiv Polytechnic Institute) in 1998 and relatively questioned to the existing explanations of the effect and invited the authors to investigate and explain the effect. 


\section{References}

[1] Netushil, A. V. (1991). Izobretenie D. Serla, kak razvitie jeffekta Gubera. Jelektrichestvo, $4,50-61$.

[2] Demin, P. (1991). Jeffekt Gubera i letajushhie tarelki. Nauka i zhizn', 7, 21-23.

[3] Kuz'min, V. V., Shpatenko, V. S. (2008). O prirode pojavlenija vrashhajushhegosja momenta v dvigatele Kosyreva_Mil'roja. Visnyk KDRU im. Ostrohradskoho, 3, 41-47.

[4] Voronkov, S. S. (2013). Jelektrodinamicheskie sily Nikolaeva. SciTecLibrary. Available at: http://www.sciteclibrary.ru/texsts/rus/stat/st5712.pdf

[5] Etkin, V. A. (2004). Termodinamicheskiy vyivod uravneniy Maksvella. Available at: http:// sciteclibrary.ru/rus/catalog/pages/7628.html

[6] Polivanov, K. M. (1982). Jelektrodinamika dvizhushhihsja tel. Moscow: Jenergoizdat, 192.

[7] Gramm, M. I. (2002). Princip minimuma i vozmozhnye objasnenija jeffekta Gubera. Jelektrichestvo, 12, 57-60.

[8] Penner, D. I., Ugarov, V. A. (1980). Jelektrodinamika i special'naja teorija otnositel'nosti. Moscow: «Prosveshhenie», 271.

[9] Nikolaev, G. V. (2003). Sovremennaja jelektrodinamika i prichiny ee paradoksal'nosti. Tomsk: Tverdynja, $149 \mathrm{~s}$.

[10] Landau, A. D., Lifshic, E. M. (1982). Teoreticheskaja fizika. Jelektrodinamika sploshnyh sred T 8. Moscow: Nauka, 621.

[11] Maksvell, Dzh. K. (1954). Izbrannye sochinenija po teorii jelektromagnitnogo polja. Moscow: Gostehizdat, 687.

[12] Sil'vestrov, A. N., Zimenkov, D. K. (2010). O prirode jeffekta Gubera. Visnik KDRU im. Ostrograds'kogo, 4, 33-38.

[13] Ostroverkhov, M. Ya., Silvestrov, A. M. (2016). Systemy i metody identyfikatsii elektrotekhnichnykh obiektiv. Kyiv: NAU, 324. 